\title{
Proposal for the new genus Allokutzneria gen. nov. within the suborder Pseudonocardineae and transfer of Kibdelosporangium albatum Tomita et al. 1993 as Allokutzneria albata comb. nov.
}

\author{
Correspondence \\ D. P. Labeda \\ david.labeda@ars.usda.gov
}

\author{
D. P. Labeda ${ }^{1}$ and R. M. Kroppenstedt ${ }^{2}$
}

\begin{abstract}
${ }^{1}$ Microbial Genomics and Bioprocessing Research Unit, National Center for Agricultural Utilization Research, Agricultural Research Service, US Department of Agriculture, Peoria, IL 61604, USA

${ }^{2}$ DSMZ - German Collection of Microorganisms and Cell Cultures, Braunschweig, Germany
\end{abstract}

\begin{abstract}
During the course of phylogenetic analyses based on $16 \mathrm{~S}$ rRNA gene sequences for all currently described taxa within the family Pseudonocardineae, it became evident that Kibdelosporangium albatum DSM $44149^{\top}$ was misplaced within the genus Kibdelosporangium and is phylogenetically most closely related to the genus Kutzneria. Chemotaxonomic analyses revealed that Kibdelosporangium albatum differed from Kutzneria in containing arabinose as well as galactose and mannose as diagnostic whole-cell sugars. The polar lipid pattern was distinct from both Kibdelosporangium and Kutzneria species in containing phosphatidylethanolamine containing 2-hydroxy fatty acids, lyso-phosphatidylethanolamine and lyso-phosphatidylmethylethanolamine as well as phosphatidylethanolamine, phosphatidylmethylethanolamine, diphosphatidylglycerol and phosphatidylglycerol. These data preclude the inclusion of this strain within the genus Kutzneria or Kibdelosporangium and a new genus is proposed, to be named Allokutzneria gen. nov. The type species of this new genus is Allokutzneria albata gen. nov., comb. nov., the type strain of which is R761- $7^{\top}\left(=\right.$ NRRL B $-24461^{\top}=$ DSM $44149^{\top}=$ ATCC $\left.55061^{\top}\right)$.
\end{abstract}

Tomita et al. (1993) described the species Kibdelosporangium albatum for a strain producing the antiviral antibiotics cycloviracins based on morphological and chemotaxonomic characteristics. During the course of phylogenetic analyses based on 16S rRNA gene sequences for all currently described taxa within the family Pseudonocardineae, it became evident that this species was misplaced within the genus Kibdelosporangium and subsequent chemotaxonomic analyses indicated that it is distinct from the phylogenetically closest genus Kutzneria.

The 16S rRNA gene sequence for Kibdelosporangium albatum DSM $44149^{\mathrm{T}}$ was obtained from GenBank (accession no. AJ512462) and aligned in the ARB package (Ludwig et al., 2004) with sequences for all other taxa within the suborder Pseudonocardineae with validly published names. The accuracy of the deposited sequence was confirmed by isolating genomic DNA and amplifying and sequencing the $16 \mathrm{~S}$ rRNA gene sequence of the equivalent strain NRRL B-24461 ${ }^{\mathrm{T}}$ from

The GenBank/EMBL/DDBJ accession number for the 16S rRNA gene sequence of Kutzneria albida NRRL B-24060 ${ }^{\top}$ is EF543522.

Details of additional sequences used in construction of Fig. 1 and a $16 S$ rRNA gene sequence similarity matrix are available as supplementary material with the online version of this paper. the ARS Culture Collection using previously described methods (Labeda \& Kroppenstedt, 2000). This confirmatory sequence was identical to that already available in GenBank and therefore was not submitted again. The sequence of the $16 \mathrm{~S}$ rRNA gene of Kutzneria albida NRRL B- $24060^{\mathrm{T}}$ was found not to be available in any of the public databases; a sequence was obtained and deposited in GenBank under accession number EF543522. Phylogenetic relationships were calculated from an alignment consisting of a total of $1403 \mathrm{bp}$ within ARB (Ludwig et al., 2004) using Kimura's twoparameter evolutionary distance method (Kimura, 1980) and the neighbour-joining method of Saitou \& Nei (1987), as well as maximum-likelihood using AxML (Felsenstein, 1989; Stamatakis et al., 2002) and maximum-parsimony using DNAPARS (Felsenstein, 1989) methods. Bootstrap support for the neighbour-joining and maximum-parsimony trees was evaluated from 1000 resamplings. Genomic DNA for determination of mol\% $\mathrm{G}+\mathrm{C}$ content by the method of Marmur \& Doty (1962) was isolated from biomass grown for 5 days with shaking at $28{ }^{\circ} \mathrm{C}$ on DSMZ medium no. 554 broth using PowerMicrobial Maxi DNA isolation kits (Mo Bio Laboratories).

Biomass for chemotaxonomic analyses was grown on DSM medium no. 554 broth incubated with shaking at 


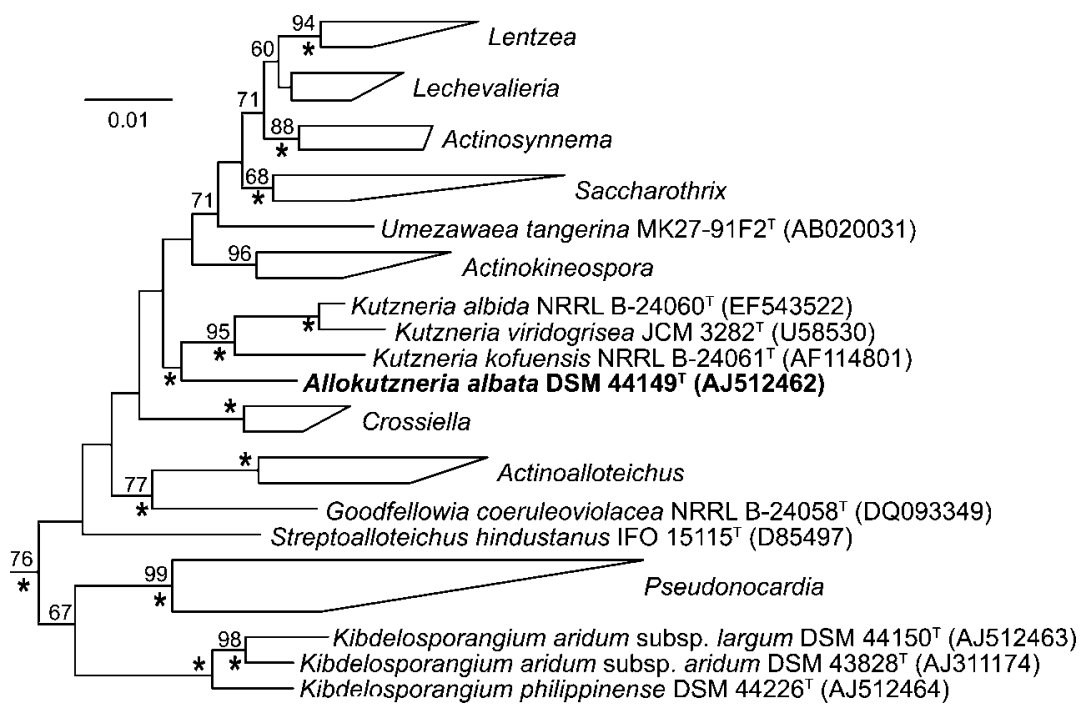

Fig. 1. Phylogenetic tree for taxa of the suborder Pseudonocardineae calculated within ARB (Ludwig et al., 2004) from almostcomplete 16S rRNA gene sequences using Kimura's two-parameter evolutionary distance method (Kimura, 1980) and the neighbourjoining method of Saitou \& Nei (1987) illustrating the taxonomic position of Allokutzneria albata DSM $44149^{\top}$ (=NRRL $\mathrm{B}-24661^{\mathrm{T}}$ ) relative to species of Kibdelosporangium, Kutzneria and the other taxa within the suborder. Percentages at nodes represent levels of bootstrap support from 1000 resampled datasets; values less than $60 \%$ are not shown. Asterisks indicate corresponding branches that were also recovered in the maximum-likelihood (Felsenstein, 1989; Stamatakis et al., 2002) and maximum-parsimony (Felsenstein, 1989) trees. Bar, 0.01 nucleotide substitutions per site. The taxa and sequences included in the genus groups are detailed in Supplementary Table S1.
200 r.p.m. for 5 days. The biomass was killed by autoclaving, collected by centrifugation and washed with sterile deionized water before freeze drying. The analyses were done using methods described previously (Grund \& Kroppenstedt, 1989; Minnikin et al., 1984; Saddler et al., 1991; Sasser, 1990).

As can be seen in Fig. 1, strain DSM $44149^{\mathrm{T}}$ is more closely related phylogenetically to species of the genus Kutzneria than to the genus Kibdelosporangium, and the tree topography in this region is supported by DNA distance- neighbour-joining, maximum-parsimony and maximumlikelihood methods. The $16 \mathrm{~S}$ rRNA gene sequence of strain DSM $44149^{\mathrm{T}}$ exhibits $94.7-95.6 \%$ similarity to those of all species of Kibdelosporangium and 95.6-97.0\% similarity to Kutzneria species (see Supplementary Table S2, available in IJSEM Online).

The whole-cell sugar pattern of strain DSM $44149^{\mathrm{T}}$ consisted of arabinose, galactose and mannose; the presence of arabinose is absolutely distinct from Kutzneria, the phylogenetically nearest neighbouring genus, and confirms the

Table 1. Comparison of the chemotaxonomic profile of Allokutzneria albata gen. nov., comb. nov. with those of the phylogenetically nearest genera and Kibdelosporangium

Components are listed in descending order of abundance. ND, No data available.

\begin{tabular}{|c|c|c|c|c|}
\hline Taxon & Whole-cell sugar pattern ${ }^{\star}$ & Phospholipids $\dagger$ & $\begin{array}{c}\text { Predominant } \\
\text { menaquinone }(s)\end{array}$ & $\begin{array}{c}\text { DNA G + C } \\
\text { content }(\mathrm{mol} \%)\end{array}$ \\
\hline Allokutzneria albata & Ara, Gal, Man & $\begin{array}{l}\text { PE, PME, OH-PE, PI, lyso-PME, DPG, } \\
\text { PG, lyso-PE }\end{array}$ & MK-9 $\left(\mathrm{H}_{4}\right)$ & 71.6 \\
\hline Crossiella & Gal, Man, Rha, Rib & PE, DPG, PI, PIM, PME & MK-9 $\left(\mathrm{H}_{4}\right)$ & 71.4 \\
\hline Actinoalloteichus & Glc, Gal, Man, Rib & PIM, PI, PG, DPG, PME & $\mathrm{MK}-9\left(\mathrm{H}_{4}\right)$ & $72-72.5$ \\
\hline Goodfellowiella & Gal, Rib & PE, DPG, OH-PE, PME & MK-9 $\left(\mathrm{H}_{4}\right)$, MK-10 $\left(\mathrm{H}_{4}\right)$ & 69.2 \\
\hline Kibdelosporangium & Ara, Gal, Glc, Rha & PE, PME, PG, PI & MK-9 $\left(\mathrm{H}_{4}\right)$ & 66 \\
\hline Kutzneria (all species) & Gal, Rha & PE, DPG, PI, PG, PME & MK-9 $\left(\mathrm{H}_{4}\right)$ & $70.3-70.7$ \\
\hline Streptoalloteichus & Gal, Man, Rha, Rib & PE, DPG, PI, PIM, DPG, PME & MK-9 $\left(\mathrm{H}_{6}\right)$, MK-10 $\left(\mathrm{H}_{6}\right)$ & ND \\
\hline
\end{tabular}

*Ara, Arabinose; Gal, galactose; Glc, glucose; Man, mannose; Rha, rhamnose; Rib, ribose.

$\dagger$ DPG, Diphosphatidylglycerol; PE, phosphatidylethanolamine; lyso-PE, PE where one fatty acid chain is missing from the glycerol backbone; OHPE, PE with hydroxy fatty acids; PG, phosphatidylglycerol; PI, phosphatidylinositol; PIM, PI mannosides; PME, phosphatidylmethylethanolamine; lyso-PME, PME where one fatty acid chain is missing from the glycerol backbone. 
chemotaxonomic data originally reported by Tomita et al. (1993). The phospholipid profile observed for this strain (Supplementary Fig. S1) is quite distinct from those of described species of Kibdelosporangium and Kutzneria and contains both lyso-phosphatidylmethylethanolamine and lyso-phosphatidylethanolamine in addition to phosphatidylethanolamine, phosphatidylmethylethanolamine, phosphatidylethanolamine containing 2-hydroxy fatty acids, diphosphatidylglycerol and phosphatidylglycerol. A comparison of the chemotaxonomic properties of strain DSM $44149^{\mathrm{T}}$ with those of the genus Kibdelosporangium and phylogenetically closely related genera is shown in Table 1 . The fatty acid profile of strain DSM $44149^{\mathrm{T}}$ is also distinct from those of members of Kibdelosporangium and the phylogenetically nearest genera (Table 2).

Observation of growth of strain DSM $44149^{\mathrm{T}}$ on various media typically used for characterization of actinomycetes (Shirling \& Gottlieb, 1966) using the light microscope also confirmed the morphological description of Tomita et al. (1993); large sporangial bodies typical of either the genus Kutzneria or Kibdelosporangium were observed on relatively minimal growth medium (i.e. Czapek's sucrose agar).

Strong consideration was given to the transfer of this species to Kutzneria as a new combination, since this strain appears phylogenetically most closely related to the species of that genus. However, the chemotaxonomic properties of strain DSM $44149^{\mathrm{T}}$ and, in particular, the presence of arabinose as a whole-cell sugar and lyso-phosphatidylethanolamine and lyso-phosphatidylmethylethanolamine as diagnostic phospholipids preclude its inclusion in the genus Kutzneria or in any of the phylogenetically closely related genera. On the basis of this substantial difference in chemotaxonomic properties, the creation of a new genus, Allokutzneria gen. nov., is therefore proposed, with Allokutzneria albata comb. nov. as the type species.

\section{Description of Allokutzneria gen. nov.}

Allokutzneria (Al.lo.kutz.ne'ri.a. Gr. adj. allos other; N.L. fem. n. Kutzneria a bacterial generic name; N.L. fem. n. Allokutzneria the other Kutzneria, referring to the fact that it is phylogenetically close to Kutzneria but chemotaxonomically distinct).

The description is generally consistent with the original description of Kibdelosporangium albatum by Tomita et al. (1993). Form sporangium-like bodies containing hyphae but not spores and also produce aerial chains of spores. Substrate mycelium is subject to varying degrees of fragmentation. Cell-wall diamino acid is meso-diaminopimelic acid. Whole-cell hydrolysates contain arabinose, galactose and mannose. Cell-wall acyl type is acetyl. Principal phospholipids include phosphatidylethanolamine, phosphatidylmethylethanolamine, phosphatidylethanolamine containing 2-hydroxy fatty acids, lysophosphatidylmethylethanolamine, diphosphatidylglycerol, phosphatidylglycerol and lyso-phosphatidylethanolamine.
Table 2. Fatty acid content of strain DSM $44149^{\top}$, members of phylogenetically closely related genera and Kibdelosporangium aridum subsp. aridum

Strains: 1, Allokutzneria albata DSM 44149 ${ }^{\mathrm{T}}$; 2, Actinoalloteichus cyanogriseus DSM $43889^{\mathrm{T}}$ (data from Tamura et al., 2000); 3, Crossiella cryophila DSM $44230^{\mathrm{T}} ; 4$, Kibdelosporangium aridum subsp. aridum DSM $43828^{\mathrm{T}}$; 5 , Kutzneria viridogrisea DSM $43828^{\mathrm{T}}$ (data from Stackebrandt et al., 1994); 6, Streptoalloteichus hindustanus DSM $44523^{\mathrm{T}}$. Data were obtained in this study unless indicated. Values are percentages of total fatty acids. tr, Trace; -, not detected/not reported. Major components $(\geqslant 10 \%)$ are highlighted in bold.

\begin{tabular}{|c|c|c|c|c|c|c|}
\hline Fatty acid & 1 & 2 & 3 & 4 & 5 & 6 \\
\hline iso- $14: 0$ & 6.4 & 5.0 & 0.7 & 5.2 & - & - \\
\hline $14: 0$ & - & - & - & 1.8 & - & - \\
\hline iso- $15: 0$ & 6.0 & 15.0 & 40.0 & 8.7 & 2.7 & 34.2 \\
\hline anteiso- $15: 0$ & 0.5 & 10.0 & 2.2 & 12.7 & - & 10.7 \\
\hline $15: 1(c 9)$ & 3.2 & - & 3.8 & - & - & - \\
\hline $15: 0$ & 2.0 & $\operatorname{tr}$ & 2.6 & 0.7 & 1.6 & - \\
\hline iso- $16: 1$ & 10.5 & 8.0 & 3.2 & 6.0 & 0.6 & - \\
\hline iso- $16: 0$ & 42.5 & 19.0 & 10.7 & 34.5 & 30.3 & 2.6 \\
\hline $16: 1(c 9)$ & 1.5 & 2.0 & 3.9 & 0.3 & 3.8 & 0.6 \\
\hline iso-15:0 $2-\mathrm{OH}$ & - & - & - & 4.2 & - & - \\
\hline anteiso-15:0 2-OH & - & - & - & 2.5 & - & - \\
\hline $16: 0$ & 1.6 & 2.0 & 2.2 & 1.5 & - & - \\
\hline iso-16:0 10-methyl & - & - & 0.9 & - & - & - \\
\hline 16:0 10-methyl & - & - & - & 0.6 & 8.6 & - \\
\hline iso- $17: 1$ & - & - & - & - & - & 14.5 \\
\hline anteiso-17: 1 & - & - & - & 0.4 & - & 1.2 \\
\hline iso- $17: 0$ & 2.3 & 3.0 & 10.3 & 1.0 & 6.2 & 10.6 \\
\hline anteiso-17:0 & 0.8 & 20.0 & 1.2 & 10.8 & 7.5 & 22.8 \\
\hline $17: 1(c 9)$ & 8.0 & - & 2.3 & - & 2.1 & 1.0 \\
\hline iso- $16: 02-\mathrm{OH}$ & - & - & - & 5.4 & 11.7 & - \\
\hline $17: 0$ & 3.8 & $\operatorname{tr}$ & 1.8 & 0.4 & 4.3 & - \\
\hline 17:0 10-methyl & - & - & - & - & 5.9 & - \\
\hline iso- $16: 03-\mathrm{OH}$ & 3.0 & - & - & - & - & - \\
\hline iso- $18: 0$ & 1.0 & - & - & 0.3 & 0.9 & - \\
\hline $18: 1(c 9)$ & 1.0 & - & - & - & 0.8 & - \\
\hline anteiso-17:0 2-OH & - & - & - & - & 4.5 & - \\
\hline iso-17:0 $3-\mathrm{OH}$ & 3.8 & - & - & 0.9 & - & - \\
\hline anteiso-17:0 $3-\mathrm{OH}$ & - & - & 4.1 & - & - & 0.3 \\
\hline $17: 03-\mathrm{OH}$ & 0.7 & - & - & 2.1 & - & - \\
\hline $18: 0$ 10-methyl & - & - & - & - & 1.5 & - \\
\hline anteiso-19:0 & - & - & - & - & - & 0.5 \\
\hline
\end{tabular}

Menaquinones are predominantly MK-9 $\left(\mathrm{H}_{4}\right)$ with traces of MK-9 $\left(\mathrm{H}_{2}\right)$, MK-9 $\left(\mathrm{H}_{6}\right)$ and MK-10 $\left(\mathrm{H}_{4}\right)$. Mycolic acids are not present. Major fatty acid components are iso- and anteiso-branched fatty acids. The type species is Allokutzneria albata.

\section{Description of Allokutzneria albata (Tomita et al. 1993) comb. nov.}

Allokutzneria albata (al.ba'ta. N.L. fem. adj. albata clothed in white, referring to the colour of the aerial mycelium and the non-chromogenicity of the organism). 
Basonym: Kibdelosporangium albatum Tomita et al. 1993.

A description of the physiological and morphological characteristics of this taxon has been published previously by Tomita et al. (1993). In addition to the properties described above for the genus, the $\mathrm{G}+\mathrm{C}$ content of the DNA of the type strain is $71.7 \mathrm{~mol} \%\left(T_{\mathrm{m}}\right)$. The type strain is $\mathrm{R} 761-7^{\mathrm{T}}\left(=\mathrm{NRRL} \quad \mathrm{B}-24461^{\mathrm{T}}=\mathrm{DSM} 44149^{\mathrm{T}}=\right.$ ATCC $\left.55061^{\mathrm{T}}\right)$.

\section{Acknowledgements}

The able technical assistance of E. N. Hoekstra for physiological characterization and G. Poetter for chemotaxonomic analyses is gratefully acknowledged. Names are necessary to report factually on available data; however, the USDA neither guarantees nor warrants the standard of the product, and the use of the name by USDA implies no approval of the product to the exclusion of others that may also be suitable.

\section{References}

Felsenstein, J. (1989). PHYLIP (phylogeny inference package) version 3.5.1. Distributed by the author. Department of Genome Sciences, University of Washington, Seattle, USA.

Grund, E. \& Kroppenstedt, R. M. (1989). Transfer of five Nocardiopsis species to the genus Saccharothrix Labeda et al. 1984. Syst Appl Microbiol 12, 267-274.

Kimura, M. (1980). A simple method for estimating evolutionary rates of base substitutions through comparative studies of nucleotide sequences. J Mol Evol 16, 111-120.

Labeda, D. P. \& Kroppenstedt, R. M. (2000). Phylogenetic analysis of Saccharothrix and related taxa: proposal for Actinosynnemataceae fam. nov. Int J Syst Evol Microbiol 50, 331-336.

Ludwig, W., Strunk, O., Westram, R., Richter, L., Meier, H., Yadhukumar, Buchner, A., Lai, T., Steppi, S. \& other authors
(2004). ARB: a software environment for sequence data. Nucleic Acids Res 32, 1363-1371.

Marmur, J. \& Doty, P. (1962). Determination of the base composition of deoxyribonucleic acid from its thermal denaturation temperature. $J$ Mol Biol 5, 109-118.

Minnikin, D. E., O'Donnell, A. G., Goodfellow, M., Alderson, G., Athalye, M., Schaal, A. \& Parlett, J. H. (1984). An integrated procedure for the extraction of bacterial isoprenoid quinones and polar lipids. J Microbiol Methods 2, 233-241.

Saddler, G. S., Tavecchia, P., Lociuro, S., Zanol, M., Colombo, E. \& Selva, E. (1991). Analysis of madurose and other actinomycete whole cell sugars by gas chromatography. J Microbiol Methods 14, 186-191.

Saitou, N. \& Nei, M. (1987). The neighbor-joining method: a new method for reconstructing phylogenetic trees. Mol Biol Evol 4, 406426.

Sasser, M. (1990). Identification of bacteria by gas chromatography of cellular fatty acids, MIDI Technical Note 101. Newark, DE: MIDI Inc.

Shirling, E. B. \& Gottlieb, D. (1966). Methods for characterization of Streptomyces species. Int J Syst Bacteriol 16, 313-340.

Stackebrandt, E., Kroppenstedt, R. M., Jahnke, K.-D., Kemmerling, C. \& Gürtler, H. (1994). Transfer of Streptosporangium viridogriseum (Okuda et al. 1966), Streptosporangium viridogriseum subsp. kofuense (Nonomura and Ohara 1969), and Streptosporangium albidum (Furumai et al. 1968) to Kutzneria gen. nov. as Kutzneria viridogrisea comb. nov., Kutzneria kofuensis comb. nov., and Kutzneria albida comb. nov., respectively, and emendation of the genus Streptosporangium. Int J Syst Bacteriol 44, 265-269.

Stamatakis, A. P., Ludwig, T., Meier, H. \& Wolf, M. J. (2002). AxML: a fast program for sequential and parallel phylogenetic tree calculations based on the maximum likelihood method. Proc IEEE Comput Soc Bioinform Conf 1, 21-28.

Tamura, T., Liu, Z., Yamei, Z. \& Hatano, K. (2000). Actinoalloteichus cyanogriseus gen. nov., sp. nov. Int J Syst Evol Microbiol 50, 14351440.

Tomita, K., Hoshino, Y. \& Miyaki, T. (1993). Kibdelosporangium albatum sp. nov., producer of the antiviral antibiotics cycloviracins. Int J Syst Bacteriol 43, 297-301. 